\title{
REFLECTIONS
}

\section{The Irreverent Nature of Evidence}

Zachary Flake, MD

Fort Collins Family Medicine Program Fort Collins, Colo
Conflict of interest: none reported

\section{CORRESPONDING AUTHOR}

Zachary Flake, MD Fort Collins Family Medicine Residency Program 1025 Pennock Place Fort Collins, CO 80524 flakza@pvhs.org

\begin{abstract}
A few months ago, I had to tell one of my attending physicians that he was wrong. His belief was based on experience, but my assertion was based on evidence. This debate, and many like it, reveals a reevaluation of the role of information in medical decisions and the doctor-patient relationship.
\end{abstract}

Ann Fam Med 2005;3:271-272. DOI: 10.1370/afm.316.

1 he graying internist stared at the board and readied his chalk. So far, my case presentation at morning report had gone smoothly. Then, without a word, he held up his hand. I halted. He lowered his glasses and looked over the rims. "You transfused her? Even with her history of heart failure?"

"Yessir," I defended the decision. "She has symptomatic anemia."

"And how will you monitor for fluid overload?"

"I ordered a brain natriuretic peptide on admission and will repeat it tomorrow morning," I proposed.

"Ha!" he yelped and dropped his glasses on the table. "What ever happened to JVD and gallops and rales?"

I knew the correct response, but I couldn't verbalize it. Instead, I lowered my head and focused on the stack of papers before me. As I cowered, our family medicine attending physician, an outspoken woman trained in the era of evidence, came to my defense. "Let's face it," she reminded him, "the sensitivity and specificity of physical findings in congestive heart failure are terrible. The BNP is a much better way to follow fluid status."

The internist stepped back. We had ventured into statistics, and this was shaky ground. "I suppose you are correct," he conceded. He turned back to me. "What happened next?"

The debate over brain natriuretic peptide and many others like it are becoming increasingly common in hospitals and clinics across the country. They represent a surprising development in medicine during the last decade-the reliance on evidence to make decisions. This shift to evidencebased decision making is surprising because clinical practice hasn't been that way all along. When I entered medical school, I assumed (as many patients do) that decisions were based on studies, investigations, and trials. As I've watched my mentors and my colleagues throughout training, I've come to the remarkable conclusion that many physicians rely on something less quantitative but infinitely more visceral—experience. They teach with such statements as, "I know the studies say this ... but one time I had that happen." Their experience-based practices are founded on common sense, but they are also sprinkled with isolated, frequently nonrepresentative, cases that cling to their memories because the cases are associated with the vivid emotions of being rebuked or even sued. More than I ever realized, medical decisions are human decisions, frequently based on instinct, personal interactions with a patient, and even how a doctor feels on a particular day.

Medical decisions will always be human ones, but the foundation for these judgments is changing. Mine is the evidence-based generation. We 
refuse to accept "because that has worked in the past" as justification for any decision. At the interface between experience and evidence, as in our morning report, conflict is frequent. We no longer learn exclusively from the experience of our mentors. When they offer an approach, we accept it cautiously. With this transition comes healthy questioning, sometimes even disrespect, about the source and the quality of information.

Lately I've been thinking this dispute is more than generational. Technology has forced us to reevaluate completely the role of information in medicine. As serious consumers, modern physicians must become evidence connoisseurs. My colleagues discuss the value of MDConsult, UpToDate, and InfoPOEMs, and we debate the usefulness of intention-to-treat analyses. When our mentors seek information, it is often derived from single sources and frequently based more on experience. We evaluate levels of evidence and scan for the most recent studies or meta-analyses. While the graying internist squints at the PDR, we tap away at our PDAs. Even so, we're all beginning to question how our reliance on evidence affects our relationships with patients.

It's hard for one generation of physicians to accept the approach of another. Older physicians lament the declining physical examination skills and loss of the art of medicine in their apprentices. Younger physicians deride older physicians as out-of-date and nostalgic. Older physicians rely on their central (as opposed to peripheral) brains to make point-of-care decisions and regard PDAs as crutches that can only soften the minds of younger physicians. Younger physicians have accepted that they cannot know everything, but that they must know how to find information quickly and evaluate its quality.

I suggest that the thoughtful family physician can learn something from both perspectives. The evidencebased approach certainly has something to offer-we realize that information mastery is no longer optional, it is a core requirement in a doctor's tool bag. We nimbly navigate an exponentially increasing library of medical evidence, and more than any generation in the past, we think in terms of efficiency and outcomes. We also tend to think in terms of machines and mechanics. All too often we view medicine from the outside, as huge groups of study participants viewed through various numbers and images.

Our experience-based advisors remind us that we have answered a noble and compassionate call. They personify an era when the doctor-patient relationship existed on a personal level with fewer distractions from laboratory tests and radiographs, an era when listening was a doctor's most effective skill. They come from a time when a study group was an $\mathrm{N}$ of 1 and doctors had a personal understanding of individual patients, and they use those understandings to make intuitive and intimate decisions. As we attempt to define our profession in this century, one of our greatest challenges is to remember the relationships that got us here. The mindful physician incorporates evidence and surveys outcomes, but never at the expense of a personal interaction with a patient.

In his essay "Leech, Leech, Et Cetera," Lewis Thomas observes that modern clinicians have made a dangerous pact. ${ }^{1}$ We crave technology and the information it provides, but in exchange we distance ourselves from patients and risk becoming simple technicians. The stethoscope, for example, magnifies visceral reverberations at the expense of a literal space between doctor and patient that did not exist before. Taken to the extreme, a radiologist can sit in his bedroom and use a CT scan to make a diagnosis that is more specific than the diagnosis of the bedside physician. Today, he notes, patients spend more time talking with the admissions and billing departments than with their doctor.

I'm trying not to let that happen to my patients. I paid attention to the BNP results, and I based my clinical decisions on them. I monitored the outcomes and prescribed medicines because they have improved morbidity and mortality in large studies. I've also come to realize that, whether he realized it or not, the graying internist was asking me not simply to look at my patient's neck and listen to her chest; he was urging me to be with my patient. When I look in the mirror some nights and see the technician that Thomas predicted, I wonder whether I might have something to learn from the internist after all.

To read or post commentaries in response to this article, see it online at http://www.annfammed.org/cgi/content/full/3/3/271.

Key words: Evidence-based medicine; medical informatics; family practiceleducation

Submitted October 7, 2004; submitted, revised, January 12, 2005; accepted January 28, 2005.

\section{References}

1. Thomas L. Leech, leech, et cetera. In: The Youngest Science: Notes of a Medicine-Watcher. New York, NY: Penguin Book 1995. 